\title{
Evaluating Educational Groups' Function of High Schools in Tehran on the Basis of Krek Patrick
}

\author{
Mohadeseh Sadat Banoofatemeh $^{1}$, Mohammad Sadegh Bijandi ${ }^{2} \&$ Fatemeh Parasteh $^{1}$ \\ ${ }^{1}$ Department of Educational planning, college of psychology, Karaj branch, Islamic Azad University, Karaj, Iran \\ ${ }^{2}$ Department of Education, Faculty of Human Science, University of Science and Culture, Tehran, Iran \\ Correspondence: Mohammad Sadegh Bijandi, Department of Education, Faculty of Human Science, University \\ of Science and Culture, Tehran, Iran
}

Received: September 20, 2016

Accepted: November 1, 2016

Online Published: January 30, 2017

doi:10.5539/ies.v10n2p114

URL: http://dx.doi.org/10.5539/ies.v10n2p114

\begin{abstract}
Nowadays, checking human sciences situation in valuation educational system in Iran is very important. They who educated in Iran's educational system, then tested higher education one of the most sophisticated countries, find well that one of the most important distinctions between two systems is difference of situation and human science value. The aim of this research is evaluating educational groups' function of human sciences area in high schools in Tehran due to Krek Patrick Model in 4 levels (reaction, behavior, learning an results). Statistical population of all teachers of educational groups of schools in Tehran by number... and sample volume according to Cochran formula is 359 that selected by clustered sampling among teachers who are members of educational groups of human sciences area. To collect data from questionnaire, researcher uses four above levels. Formal and content validity are accepted by 15 authorities and reliability that is calculated by using Cronbach Alpha in 4 levels (reaction, behavior, learning and results) is $0.823,0.795,0.861$, and 0.742 respectively. Study method is descriptive and survey and adding to descriptive indexes, to analyze data, one group $t$, independent $t$, analyzing multivariable variance and regression are used. Results of one group t test showed that educational groups' function of human sciences area is suitable due to Krek Patrick Model in four studied levels. Also results of independent test $\mathrm{t}$ and analyzing multivariable variance showed that there is a meaningful difference in educational groups' function according to Krek Patrick Model and also in various levels among women and men. Finally, results of regression showed that history of work predicts educational groups' function according to Krek Patrick model.
\end{abstract}

Keywords: evaluating function, educational groups, Krek Patrick Model

\section{Introduction}

Education in any society is a basic pillar and effective institute and changing and dynamics fits with needs, is its inseparable component which any change and evolution in it must be accompanied with wide and deep thought, because any mistake can effect irreversibly and dangerously on group of people and state. But in another hand, necessity of any change is having program and necessity of any program is establishing change, intervene whom are effected their life by applying it. This must be done from determining goals and planning to applying and evaluating (Evancevich, 2001, quoted from Fateminia, 2013).

Educational groups as educational, developing and research meetings have created by this thought while establish interaction and creative relation between teachers and by their participation in education, use scientific, instructional and professional experiences and information of authorities and teachers in relation with teaching methods, measurement methods and valuating educational progress and finally improving educational quality. Since organization's staffs' activities in form of groups, their tasks are done and coordinated better, managers by using groups, coordinate staffs activities to apply organization' goals (Maroufi, Kiamanesh, Mehrmohammadi, \& Aliasgari, 2007).

Due to tasks on charge of educational groups, it is necessary to evaluate their function. Educational groups' tasks are observance on educational activities and technology in schools, developing and generalizing teachers' effective experiences and approaches to students by course groups, attend to actualize course matters and integrate concepts with students' life and experiences to making learning deeper, preparation and composing 
executive calendar annually of educational activities in educational course in the line of educational goals (Safavi, 2014).

Importance of educational groups addressed to educational organization expectations in relation to enforcement of human force by applying educational workshops, preparing educational packets, brochure and educational leaflets, checking and analyzing problems of course books, preparing functional program for any graduate degrees and offering necessary approaches to improve learning process and highlighted on making effective and constant relation with schools' teachers (Smith, 2004).

Educated and skillful human force in educational groups in any section of education is motor power of equal development and comprehensive progress is education organization and these educational groups conceived as highest capital of any educational system materially and spiritually. Having exact and stable programs in education is updating educational content and by applying it in relation with elementary degrees to high school for which state education organization is responsible, as we done it correctly, we can pass passage of development in state quickly and by acceptable acceleration. But unfortunately, in recent years, ministry takes procedure as far as there is no convergence in education policies to increase education quality and developing and educating human force and improving educational groups (Momeni et al., 2010).

Checking human sciences situation in valuating system and Iran's educational system is important. Those educated in Iran's educational system, then experienced higher education in sophisticated states, well know that one of the most important differences between two systems is difference of situation and value of human sciences. Due to above statements and importance and situation of human sciences field, in this research, this field has selected as educational group. Therefore, this research wants to answer this question whether educational groups' function of human sciences area of high schools in Tehran, due to Krek Patrick Model in interaction level, learning, changing behavior and also in access to educational goals is effective?

\section{Investigation Theoretical Foundations}

\subsection{History}

Eshaghian (2010) in an investigation under title evaluating effectiveness of educational courses by means of international standard and Krek Patrick Model which done it in health services insurance office in Isfahan province, concludes that behavior aspects and results are most important in evaluating effectiveness of educational courses in health services insurance office in Isfahan province. Also after offering educational courses in any units by using these dimensions and key indexes, one can find weakness and strength of that unit in any dimension and identifies dimensions which need investment and emphasis, and steps to remove weakness and improve improvable points.

Zarei (2010) investigates to evaluate effectiveness of educational courses of educating teacher in Bushehr in 2007-2008 according to Krek Patrick Model, results of this research shows that these courses in first, third, and fourth degrees has been effective, but in second degree, effective learning is not suitable.

Farlei (2009) studies to evaluate effectiveness of educational courses of municipality organization's staffs according to Krek Patrick Model, results of this research shows that these courses in first, second, and fourth degrees has been effective, but in point of view of managers of those staffs, in fourth degree, effectiveness is not suitable.

Mahmoudi-Omrabadi (2009) in a project, checks educational courses while service municipality's staffs in Arak by emphasis on Krek Patrick Model. Results from learning reaction level, skill and results show that staffs reaction to the course. Education course effects on their skill and according to managers, has suitable results.

Abtahi (2003) in a research under title evaluating educational programs based on computer, used Krek Patrick patterns that evaluation of this set of programs in reaction level (users' satisfaction), learning (change in one of science, view and skill dimensions), behavior (usage amount of learned matters in work environment) and results include losses, increase effectiveness business amount and so on.

Anderson (2008) in a research's results reports that learners due to important factors in one course, according to Krek Patrick Model, react well against applied educational course.

Steven (2000) checked learners' reaction in short time courses of education according to first level of Krek Patrick Model. Results showed that learners were satisfied completely from holding short time courses except two courses. 


\subsection{Evaluating Function}

Evaluating educational function, that is, systematic collecting and interpreting are witnesses that lead to value judgement due to a work that happens (Fathi-Vajargah, 2008).

\subsection{Educational Groups}

Educational groups as quality cores can meditate up relation between functional teachers and experts well; this relation finally leads to advance education and its improvement. Hence educational groups are called as thought producers and educational planners in analyzing books content. They must achieve expertise and creativity to can be effective in workshop and professional meetings (Safavi, 2014).

\subsection{Krek Patrick Method}

Krek Patrick method wants to measure program's effects and in this area, identifies various levels for it (Fathi-Vajargah, 2008).

Reaction evaluating; it is very reaction that participants show about the program in that educational program that is achieved by questionnaire, interview ...

Evaluating behavior; is way and amount of changes that result in participants' behavior in educational course which can be revealed by continuing evaluating real environment.

Evaluating learning; is very determining learning skills, technics, and realities which individuals have learned that one can find it by pretest and posttest.

\section{Investigation Questions}

Due to main purpose of this investigation that checks educational group's function of human sciences area in Krek Patrick Model levels, hence since it divides Krek Patrick Model to four levels, it is necessary that any of these levels are checked which appeared as four questions in relation with educational groups' function. Also one of the controversial discussions in checking function is one's gender because men and women show different function. So gender appears in relation with educational groups and Krek Patrick Model levels as two questions. Another important question is one's history that directly effects on function. So there is a main question and seven subsidiary questions.

\subsection{Main Question}

- Does educational groups function of human sciences area in Krek Patrick Model levels is suitable?

\subsection{Subsidiary Questions}

- Does educational groups' function of human sciences area in reaction level of Krek Patrick Model levels is suitable?

- Does educational groups' function of human sciences area in changing behavior level of Krek Patrick Model levels is suitable?

- Does educational groups' function of human sciences area in learning level of Krek Patrick Model levels is suitable?

- Does educational groups' function of human sciences area in accessibility level to educational goals of Krek Patrick Model levels is suitable?

- Does educational groups' function of human sciences area of women and men according to Krek Patrick Model levels is different?

- Does educational groups' function of human sciences area in Krek Patrick Model levels (reaction, behavior, learning, results) of women and men is different?

- Does work history predicts educational groups function of human sciences area according to Krek Patrick Model?

\section{Investigation Method}

This research purposely is functional and methodologically is descriptive-survey. Number of statistical population of this research of all teachers of high schools in human sciences area in Tehran in 2014-2015 is 8000. Sample volume according to table Morgan is 357, due to imperfect data possibility, number of research sample is 400 , and clustering multistage sampling method is used. First, education sections in Tehran are divided to north, south, west, east and center and any section is considered as one cluster. From any cluster accidentally one section, and from any section, 4 girl schools, and 4 boy schools, and from 10 teachers $(8 * 10=80)$ and finally 400 
$(5 * 80=400)$ teachers selected as research sample. Then questionnaire with 45 questions evaluates educational groups' activities according to Krek Patrick Model in four studied levels.

In this research, researcher to assurance of validity, provides questionnaire with some experienced authorities in this area, and wants them to evaluate questionnaire. Due to experts' guidance and comments, any question that accepted less, according to masters, is deleted or adjusted. Finally, they have confirmed validity formally and conceptually.

They offer questionnaire as form of check list for 15 teachers for reliability in evaluation. Variables' alpha is seen in Table 1.

Table 1. Cronbach alpha

\begin{tabular}{cc}
\hline Components & Cronbach alpha coefficient \\
\hline Reaction level & 0.823 \\
Behavior level & 0.795 \\
Learning level & 0.861 \\
Results level & 0.742 \\
\hline
\end{tabular}

Finally, to analyze data, one group $\mathrm{t}$ test, independent $\mathrm{t}$ test, analyzing multivariable variance and regression were tested.

\section{Research Findings}

\subsection{Descriptive Statistics}

Table 2. Separating sample for gender, marry, age, education and history are seen.

\begin{tabular}{|c|c|c|c|c|}
\hline \multicolumn{5}{|c|}{ Gender } \\
\hline \multicolumn{2}{|r|}{ Man } & & \multicolumn{2}{|r|}{ woman } \\
\hline \multicolumn{2}{|r|}{198} & & \multicolumn{2}{|r|}{161} \\
\hline \multicolumn{5}{|c|}{ Marry } \\
\hline \multicolumn{2}{|r|}{ Single } & & \multicolumn{2}{|r|}{ Married } \\
\hline \multicolumn{2}{|r|}{83} & & \multicolumn{2}{|r|}{276} \\
\hline \multicolumn{5}{|c|}{ age } \\
\hline $20-25$ & $36-30$ & $31-35$ & $36-40$ & $40-43$ \\
\hline 50 & 72 & 95 & 99 & 43 \\
\hline \multicolumn{5}{|c|}{ Education } \\
\hline \multicolumn{2}{|c|}{ Associate } & \multicolumn{2}{|c|}{ bachelor } & master \\
\hline \multicolumn{2}{|c|}{21} & \multicolumn{2}{|c|}{235} & 103 \\
\hline \multicolumn{5}{|c|}{ history } \\
\hline $1-4$ & $5-9$ & $10-14$ & $15-19$ & More than 20 \\
\hline 91 & 48 & 146 & 53 & 19 \\
\hline
\end{tabular}

Table 3. Average of components of Krek Patrick Model

\begin{tabular}{ccc}
\hline Components & Average & Number of items \\
\hline Reaction level & 33.69 & 10 \\
Behavior level & 39.19 & 11 \\
Learning level & 45.70 & 13 \\
Results level & 36.43 & 11 \\
Sum & 155.1 & 45 \\
\hline
\end{tabular}

Table 3 shows average of components of Krek Patrick Model. 


\subsection{Checking Normality of Variables}

Table 4. Normality test of research variables

\begin{tabular}{ccc}
\hline Components & Number of tests & $\mathrm{Z}$ amount \\
\hline Reaction level & 359 & 1.04 \\
Behavior level & 359 & 1.33 \\
Learning level & 359 & 1.39 \\
Results level & 359 & 1.08 \\
Sum & 359 & 1.49 \\
\hline
\end{tabular}

\subsection{Checking Main Question}

"Does educational groups' function of human sciences area in Tehran's high school in Krek Patrick Model levels is suitable?"

Table 5. Results of comparison of theoretical average and empirical average of educational groups' function in Krek Patrick Model levels

\begin{tabular}{ccccccc}
\hline Number & Theoretical average & Empirical average & Standard deviation & Freedom degree & Calculated $\mathrm{t}$ & Sig \\
\hline 359 & 112.5 & 155.1 & 26.6 & 358 & 32.2 & $0.0001^{* *}$ \\
\hline
\end{tabular}

** $\mathrm{P}<0.01$ (meaningful in 99 percent confidence level).

Due to results of Table 5, difference of theoretical average of educational groups' function due to Krek Patrick Model in 99 percent level is meaningful, and research main question is confirmed.

\subsection{Checking First Subsidiary Question}

"Does educational groups' function of human sciences area in Tehran's high school in reaction level of Krek Patrick Model is suitable?"

Table 6. Results of comparison of theoretical average and empirical average of educational groups' function in reaction level of Krek Patrick Model

\begin{tabular}{rcccccc}
\hline Number & Theoretical average & Empirical average & Standard deviation & Freedom degree & Calculated $\mathrm{t}$ & Sig \\
\hline & 25 & 33.69 & 6.86 & 358 & 27.7 & $0.0001^{* *}$ \\
\hline$* \mathrm{P}<0.01$ (meaningful in 99 percent confidence level).
\end{tabular}

Due to results of Table 6, difference of theoretical average of educational groups' function due to Krek Patrick Model in reaction level in 99 percent level is meaningful, and research first subsidiary question is confirmed.

\subsection{Checking Second Subsidiary Question}

“Does educational groups' function of human sciences area in Tehran's high school in behavior change level of Krek Patrick Model is suitable?"

Table 7. Results of comparison of theoretical average and empirical average of educational groups' function in behavior level of Krek Patrick Model

\begin{tabular}{ccccccc}
\hline Number & Theoretical average & Empirical average & Standard deviation & Freedom degree & Calculated t & Sig \\
\hline 359 & 27.5 & 39.19 & 6.86 & 358 & 34.4 & $0.0001^{* *}$ \\
\hline
\end{tabular}

** $\mathrm{P}<0.01$ (meaningful in 99 percent confidence level).

Due to results of Table 7, difference of theoretical average of educational groups' function due to Krek Patrick Model in behavior level in 99 percent level is meaningful, and research second subsidiary question is confirmed. 


\subsection{Checking Third Subsidiary Question}

"Does educational groups' function of human sciences area in Tehran's high school in learning level of Krek Patrick Model is suitable?"

Table 8. Results of comparison of theoretical average and empirical average of educational groups' function in learning level of Krek Patrick Model

\begin{tabular}{|c|c|c|c|c|c|c|}
\hline Number & Theoretical average & Empirical average & Standard deviation & Freedom degree & Calculated $\mathrm{t}$ & Sig \\
\hline 359 & 32.5 & 45.70 & 7.47 & 358 & 35.6 & $0.0001 * *$ \\
\hline
\end{tabular}

Due to results of Table 8, difference of theoretical average of educational groups' function due to Krek Patrick Model in learning level in 99 percent confidence level with empirical average (45.70) statistically is meaningful, and research third subsidiary question is confirmed.

\subsection{Checking Fourth Subsidiary Question}

"Does educational groups' function of human sciences area in Tehran's high school in access to goals level of Krek Patrick Model is suitable?"

Table 9. Results of comparison of theoretical average and empirical average of educational groups' function in learning level of Krek Patrick Model

\begin{tabular}{ccccccc}
\hline Number & Theoretical average & Empirical average & Standard deviation & Freedom degree & Calculated $\mathrm{t}$ & Sig \\
\hline 359 & 27.5 & 36.43 & 7.23 & 358 & 24.7 & $0.0001^{* *}$ \\
\hline
\end{tabular}

** $\mathrm{P}<0.01$ (meaningful in 99 percent confidence level).

Due to results of Table 9, difference of theoretical average of educational groups' function due to Krek Patrick Model in access to goals level in 99 percent confidence level with empirical average (36.43) statistically is meaningful, and research fourth subsidiary question is confirmed.

\subsection{Checking Fifth Subsidiary Question}

"Does educational groups' function of human sciences area in Tehran's high school in women and men according to Krek Patrick Model is different?"

Table 10. Results of independent $t$ test to check men and women difference in Krek Patrick Model

\begin{tabular}{ccccccc}
\hline Index & Number & Average & Standard deviation & Freedom degree & $\mathrm{t}$ amount & Meaningfulness level \\
\hline Men & 161 & 151.3 & 27.2 & 357 & 2.35 & $0.0019^{*}$ \\
Women & 198 & 157.9 & 25.7 & & & \\
\hline
\end{tabular}

* $\mathrm{P}<0.05$ (meaningful in 99 percent confidence level).

As Table 10 shows, fifth subsidiary question is confirmed by 99 percent confidence. Results represent that educational women groups' function is more than men one according to Krek Patrick Model.

\subsection{Checking Sixth Subsidiary Question}

"Does educational groups' function of human sciences area in Tehran's high school in Krek Patrick Model levels (reaction, behavior, learning, results) in women and men is different?"

To check this question, analyzing multivariable test is used.

According to results of Table 11, we conclude that meaningfulness level is more than 0.05 that shows that variance-covariance matrices are homogenous. 
Table 11. Results of MBox test

\begin{tabular}{cc}
\hline MBox's & 5.90 \\
\hline F & 0.581 \\
\hline d. $f_{1}$ & 10 \\
\hline d. $f_{2}$ & 5545 \\
\hline sig & 0.831 \\
\hline
\end{tabular}

To check correlation between dependent variables of Krek Patrick Model level (reaction, behavior, learning, results) Kroit Bartlet test is used that its results are seen in Table 12.

Table 12. Kroit Bartlet test

\begin{tabular}{cc}
\hline Likelihood relation & 0.0001 \\
\hline Chi-squared amount & 82.4 \\
\hline Freedom degree & 6 \\
\hline Meaningfulness level & 0.0001 \\
\hline
\end{tabular}

As Table 12 shows, chi-squared amount is 82.4 that have 99 percent confidence meaningfulness.

To check this hypothesis, relation to group effect (independent variable) on linear composite of Krek Patrick Model levels (reaction level, behavior level, learning level, results level), multivariable test is uses that its results are seen in Table 13.

Table 13. Results of multivariable tests

\begin{tabular}{ccccccc}
\hline Eta square & Meaningfulness level & Error freedom level & Supposed freedom degree & F & value & effect \\
\hline 0.20 & $0.032^{*}$ & 354 & 4 & 3.76 & 0.20 & Pillay effect \\
0.20 & $0.032^{*}$ & 354 & 4 & 3.76 & 0.80 & Lambadi Wickless \\
\hline
\end{tabular}

* $\mathrm{P}<0.05$ (meaningful in 99 percent confidence level).

As Table 13 shows, Pillay effect value amount is 0.20 and $\mathrm{F}$ amount is 3.76 that in 95 percent confidence level statistically is meaningful.

Table 14. Results of intergroup effects tests

\begin{tabular}{cccccccc}
\hline Eta square & sig & F & Squares sum average & Freedom degree & Squares sum & Dependent variable & Changes sources \\
\hline 0.12 & $0.037^{*}$ & 4.39 & 172.5 & 1 & 172.5 & Reaction level & \\
0.18 & $0.012^{*}$ & 6.43 & 299.2 & 1 & 299.2 & Behavior level & Dependent variables \\
0.16 & $0.018^{*}$ & 5.63 & 310.2 & 1 & 310.2 & Learning level & \\
0.11 & $0.048^{*}$ & 3.92 & 203.2 & 1 & 203.2 & Results level & \\
\hline
\end{tabular}

$*$ P $<0.05$ (meaningful in 99 percent confidence level).

As Table 14 shows, $\mathrm{F}$ amount for dependent variable of reaction level is 4.39 that statistically in 95 percent confidence is meaningful. Due to this fact that eta square for dependent variable of reaction level is 0.12 , we conclude that independent variable determines 12 percent of dependent variable of reaction level.

Also $\mathrm{F}$ amount for dependent variable in behavior level is 6.43 that statistically are meaningful in 95 percent confidence. Due to this fact that Eta square for dependent variable of behavior level is 0.18 , in result, independent variable (gender) determines 18 percent of dependent variable of behavior level.

Also $\mathrm{F}$ amount for dependent variable of learning level is 5.63 that statistically are meaningful in 95 percent confidence level. Eta square for dependent variable of learning level is 0.16 that represents that independent variable determines 16 percent of dependent variable changes of learning level.

While $\mathrm{F}$ amount for dependent variable of results level is 3.92 that statistically is meaningful in 95 percent confidence level. Above result represents difference of dependent variable in results level in independent variable (gender), and due to this fact that Eta square for dependent variable of results level is 0.11 , it represents 
that independent variable (gender) determines 11 percent of dependent variable changes in results level.

\subsection{Checking Seventh Subsidiary Question}

"Does work history predicts educational groups' function of human sciences of Tehran's high schools according to Krek Patrick Model?"

Table 15. Results of model summary of relation between work history and educational groups' function according to Krek Patrick Model

\begin{tabular}{ccccc}
\hline $\mathrm{R}$ & $\mathrm{R} 2$ & Adjusted R2 & $\mathrm{F}$ & Meaningfulness level \\
\hline 0.203 & 0.041 & 0.039 & 15.39 & $0.0001^{* *}$ \\
\hline
\end{tabular}

** $\mathrm{P}<0.01$ (meaningful in 99 percent confidence level).

As Table 15 shows, correlation coefficient amount $(\mathrm{R}=0.203)$ represents correlation between predictor variable (work history) and scale variable (educational groups' function according to Krek Patrick Model).

Table 16. Regression coefficients

\begin{tabular}{cccccc}
\hline \multirow{2}{*}{ Model } & \multicolumn{2}{c}{ Non-standard coefficients } & Standard coefficients & \multirow{2}{*}{ T } & Meaningfulness level \\
\cline { 2 - 4 } & $\mathrm{b}$ & Average standard error & Beta & & \\
\hline y-intercept & 144.6 & 2.99 & - & 48.35 & $0.0001^{* *}$ \\
\hline Work history & 0.956 & 0.244 & 0.203 & 3.92 & $0.0001 *$ \\
\hline meaningful in 99 percent confidence level) & &
\end{tabular}

** $\mathrm{P}<0.01$ (meaningful in 99 percent confidence level).

Due to results of Table 16, we see that statistical t for work history $(\mathrm{R}=3.92)$ in 99 percent confidence level is meaningful that represents that effect of standard regression coefficient $(\beta=0.203)$ of work history on educational groups' function according to Krek Patrick Model.

\section{Conclusion}

Results of one group $t$ test showed that educational groups' function of human sciences due to Krek Patrick Model in four levels (reaction, behavior, learning, results) is suitable. Then results of test suggest that educational groups must continue by advancing approach and increase own success effectively. And functional structure of educational groups has been implemented properly. Also results of independent $t$ test and multivariable variance analysis showed that educational groups' function according to Krek Patrick Model and also there is a meaningful difference in various levels, in women and men. These results can be explained to different structure of men and women in internal level (way of education and offer) and internal discussion (physiological). Then generally men and women teachers have been educated differently and any of them experienced different problems. Also man physiological structure is based on difference relation with women in emotional and sentimental discussion and in learning abilities. Then in educational groups it is necessary that due to courses, men and women are selected. Why men and women abilities are different and any group fits with some special courses. As results showed, work history predicts educational groups' function according to Krek Patrick Model, so schools can find next years' function amount from teachers' history amount. And in this line, select some as teachers who help educational groups' next function.

\section{References}

Abtahi, H. (2003). Evaluating educational programs based on computer from Krek Patrick patterns (Master thesis, Yazd University).

Anderson, B. (2008). Impact of new libriary technology on training paraprofessional staff. The Reference Librarian, 18(39), 21-29. https://doi.org/10.1300/J120v18n39_04

Eshaghian, A. (2010). Evaluating educational courses by means of international ISO standard 10015 and Krek Patrick Model (Master thesis, Azad University of Najafabad).

Fateminia, Z. (2013). Evaluating educational urban complexes according to Sip pattern (Master thesis, Islamic Azad University).

Fathi-Vajargah, A. (2008). Valuating efficiency of educational courses according to Krek Patrick pattern. 
Publication: Ayeizh, Tehran.

Gharlie, M. (2009). Evaluating efficiency of educational courses of municipality organization staffs according to Krek Patrick Model (Master thesis, Islamic Azad University).

Mahmoudi-Omrabadi, R. (2009). Checking efficiency of educational courses under task of Arak's municipality with emphasis on Krek Patrick Model (Master thesis, Islamic Azad University).

Maroufi, Y., Kiamanesh, A., Mehrmohammadi, M., \& Aliasgari, M. (2007). Valuating education quality in higher education, checking some views. Course Studies Quarterly, 1(5), 81-112.

Momeni, M. H., Karami, M., \& Mashhadi, A. (2010). Checking role of decreasing factor of interval between intended, applied and experienced course programs of higher education. Higher Education Course Studies Quarterly, 1(2), 110-112.

Safavi, A. (2014). Education methods and technics. Tehran Moaser publication.

Smith, L.(2004). Continuing professional development and workplace. Library Management, 25(4), 233.

Steven, G. L. (2000). Web-based learning: A Krik Patrick's multilevel evaluation of effectiveness. Pro Quest Dissertations and Theses (pp. 90-125).

Zarei, M. (2010). Evaluating efficiency of educational courses of educating teachers in Bushehr in 2007-2008 according to Krek Patrick Model (Master thesis, Bushehr University).

\section{Copyrights}

Copyright for this article is retained by the author(s), with first publication rights granted to the journal.

This is an open-access article distributed under the terms and conditions of the Creative Commons Attribution license (http://creativecommons.org/licenses/by/4.0/). 